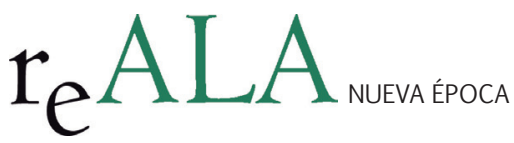

REALA, n 2, julio-diciembre 2014, ISSN: 1989-8975

DOI: http://dx.doi.org/10.24965/reala.voi2.10193

\title{
La contratación de las Entidades Locales en el nuevo paquete legislativo europeo sobre contratación pública
}

\author{
Miguel Ángel Bernal Blay \\ Facultad de Derecho. Universidad de Zaragoza. \\ mabernal@unizar.es \\ Recibido: 18 de febrero 2014 \\ Aceptado: 12 de junio 2014
}

\section{Resumen}

Tras la aprobación de un nuevo paquete legislativo europeo en materia de contratación pública se encuentran dos claros objetivos. De una parte, mejorar la eficiencia de los recursos públicos asignados a la tarea del aprovisionamiento de bienes y servicios, simplificando los procedimientos y eliminando las trabas burocráticas que perjudiquen esa eficiencia. De otro, permitir la utilización de la contratación como herramienta al servicio de determinadas políticas públicas. El presente artículo da cuenta de las novedades que presentan las nuevas Directivas en materia de contratación pública y analiza en particular las disposiciones que, de manera más especifica, tienen como destinatarias a las Entidades Locales.

Palabras clave

Contratación pública, Entidades locales, Autoridades sub-centrales

\section{Hiring Local Entities in the New European Legislative Package on Public Procurement}

\section{Abstract}

The adoption of a new EU legislative package on public procurement has two clear objectives. On the one hand, improve the efficiency of public resources allocated to the task of supplying goods and services to public Authorities. For this scope it is necessary to simplify the procedures and eliminate administrative burdens. The second scope is to allow the use of public procurement as a tool to develop certain public policies. This article analyses the new Directives on public procurement and in particular the provisions that, more specifically, are designed for local Authorities.

\section{Keywords}

Public procurement, Local Entities, sub-central Authorities 


\section{I.- EL NUEVO PAQUETE LEGISLATIVO EUROPEO EN MATERIA DE CONTRATACIÓN PÚBLICA}

\section{1.- El contexto de la reforma}

En Diciembre de 2011, la Comisión europea hizo públicas tres propuestas de Directivas en materia de contratación pública'. Dos de esas propuestas de Directiva vienen a sustituir a las actualmente vigentes Directiva 2004/17/CE del Parlamento Europeo y del Consejo, de 31 de marzo de 2004, sobre la coordinación de los procedimientos de adjudicación de contratos en los sectores del agua, de la energía, de los transportes y de los servicios postales, y Directiva 2004/18 del Parlamento Europeo y del Consejo, de 31 de marzo de 2004 , sobre coordinación de los procedimientos de adjudicación de los contratos públicos de obras, de suministro y de servicios. Serían, respectivamente, la Directiva relativa a la contratación por entidades que operan en los sectores del agua, la energía, los transportes y los servicios postales y la Directiva relativa a la contratación pública, a las que se añade, como novedad, una tercera Directiva relativa a la adjudicación de contratos de concesión.

Las nuevas Directivas de contratación pública «de cuarta generación» tienen como antecedente inmediato el Libro Verde sobre la modernización de la política de contratación pública de la UE (COM (2011) 15 final) publicado por la propia Comisión el 27 de enero de 2011. Con este Libro Verde la Comisión puso en marcha una amplia consulta pública sobre los cambios legislativos que podrían introducirse para facilitar y flexibilizar la adjudicación de los contratos y hacer posible una mejor utilización de los contratos públicos en apoyo de otras políticas. La finalidad de este Libro Verde era determinar una serie de ámbitos fundamentales que podrían ser objeto de reforma y recabar las opiniones de las partes interesadas sobre las opciones concretas de cambio legislativo. Entre las cuestiones tratadas figuraban la necesidad de simplificar y flexibilizar los procedimientos, el uso estratégico de la contratación pública para promover otros objetivos políticos, la mejora del acceso de las PYME a los contratos públicos y la lucha contra el favoritismo, la corrupción y los conflictos de intereses.

La consulta pública finalizó el 18 de abril de 2011, y obtuvo una gran participación. Se recibieron en total 623 respuestas, procedentes de una gran variedad de agentes interesados, entre ellos autoridades centrales de los Estados miembros, compradores públicos de ámbito local y regional y sus asociaciones, empresas, asociaciones industriales, personalidades del mundo académico, organizaciones de la sociedad civil (incluidos los sindicatos) y ciudadanos particulares. El mayor número de respuestas procedió del Reino Unido, Alemania, Francia y, un poco por debajo, de Bélgica, Italia, los Países Bajos, Austria, Suecia, España y Dinamarca. Los resultados de la consulta se presentaron y debatieron en una conferencia pública celebrada en Bruselas el 30 de junio de $2011^{2}$.

Además del citado Libro Verde, la Comisión Europea publicó el 24 de junio de 2011 un informe de evaluación del impacto y la eficacia de la legislación de la UE en materia de contratación pública. En dicho informe se analizaba si las Directivas de la UE sobre contratación pública 2004/17/CE y 2004/18/CE habían logrado que la transparencia y la competencia transfronteriza sirvieran para alcanzar una mejor contratación pública 3 . Particularmente interesante de este informe es el estudio de costes y beneficios de la intervención legislativa a nivel europea, centrado en gran medida en el análisis de la duración y el coste de los procedimientos. En el informe se indica, en relación con la duración de los procedimientos, que el tiempo normal que transcurre entre el envío de la convocatoria de licitación y la adjudicación es, sea cual sea el procedimiento, de 108 días, pero que la diferencia entre los poderes adjudicadores más rápidos y los más lentos es de, aproximadamente, 180 días. Gran parte del problema reside en el plazo que los poderes adjudicadores se toman para adjudicar el contrato, una vez concluido el plazo de presentación de ofertas ${ }^{4}$. En promedio, el tiempo necesario para adjudicar un contrato gira en torno a los 58 días, pudiendo ser de 45 días cuando se trata de contratos simples otorgados al precio más bajo, o de hasta 245 días si se trata de un complejo procedimiento de diálogo competitivo5. El procedimiento restringido necesita de unos 160

\footnotetext{
El texto de las mismas fue publicado en el DOUE de 5 de abril.

2 La información sobre esta conferencia se encuentra disponible a través de http://ec.europa.eu/internal_market/publicprocurement/ modernising_rules/conferences/index_en.htm

3 El 40 por ciento de las empresas señalaron que la contratación pública realizada con arreglo al procedimiento abierto es más o mucho más transparente que las adquisiciones privadas, y un 35 por ciento afirmó lo mismo refiriéndose al procedimiento restringido. Asimismo, las empresas indicaban que la contratación pública es más justa que la privada (el 33 por ciento en lo que respecta al procedimiento abierto y el 34 por ciento en lo tocante al restringido).
}

Debe advertirse no obstante que el estudio se realizó sobre contratos sometidos a las Directivas, que representan alrededor del 20 por ciento del total de contratos de obras, servicios y suministros. Solo una quinta parte del gasto público total en bienes y servicios está sujeto a lo dispuesto en las Directivas de la Unión Europea. En 2009, se publicaron más de 150000 convocatorias de licitación (procedentes de 35.000 autoridades), de conformidad con las Directivas. El valor estimado de estos contratos ascendía a 420.000 millones de euros, lo que representa aproximadamente el $20 \%$ del gasto público total en bienes, obras y servicios.

4 No le falta razón a CARBONERO GALLARDO (2012) cuando afirma que el procedimiento de contratación administrativa ha ido perdiendo agilidad y convirtiéndose en lo que actualmente es con el TRLCSP: un penoso itinerario burocrático que riñe a veces con las más elementales nociones de eficiencia, "El colapso de la contratación administrativa".

5 La duración del procedimiento de diálogo competitivo puede explicarse, en gran parte, por la naturaleza compleja de los proyectos 
días hasta la adjudicación, que es mucho más de lo que suele requerir habitualmente el procedimiento abierto (53 días hasta la adjudicación). Estas diferencias son muy significativas e inciden inevitablemente en la eficiencia y el coste de los procedimientos de contratación.

En relación con los costes del procedimiento, con arreglo a la evaluación efectuada por la Comisión, el coste medio de llevar a cabo cada procedimiento es de unos 28.000 euros. Según la Comisión, este coste puede considerarse el precio a pagar por el mantenimiento de la competencia en el mercado de los contratos públicos. El 75 por ciento de esa cifra corresponde al coste en que incurren los proveedores para preparar la oferta, y que habrá que dividir entre los 5,4 licitadores que se registran, por término medio, por cada licitación. Es de suponer que estos costes se incorporan a largo plazo a los precios de las ofertas o a los márgenes de los adjudicatarios ${ }^{6}$.

La evaluación realizada por la Comisión concluye que las Directivas sobre contratación pública han fomentado la apertura y la transparencia, lo cual ha originado una intensificación de la competencia, que se ha traducido en un ahorro de costes?.

\section{2.- Objetivos de la reforma}

La generación actual de Directivas sobre contratación pública, las Directivas 2004/17/CE y 2004/18/CE, son el último paso de una larga evolución que comenzó en 1971 con la adopción de la Directiva 71/305/CEE. La finalidad principal de estas Directivas era garantizar unos procedimientos transparentes y no discriminatorios, aunque también se mencionaban en ellas serie de objetivos relativos a la integración en este marco de otras políticas, como las de protección del medio ambiente y las normas sociales o la lucha contra la corrupción.

Pero ahora es momento para abordar otros retos a través de la contratación pública, en particular, los que presenta la estrategia Europa 2020 para un crecimiento inteligente, sostenible e integrador ${ }^{8}$. La Comisión europea plantea una visión de la economía social de mercado competitiva de Europa para la próxima década basada en tres prioridades interrelacionadas y que se refuerzan mutuamente:

- desarrollo de una economía basada en el conocimiento y la innovación;

- promoción de una economía con pocas emisiones de carbono, que haga un uso más eficiente de los recursos y que sea competitiva, $y$

- fomento de una economía con alto nivel de empleo que tenga cohesión social y territorial.

La contratación pública desempeña un papel clave en esa estrategia Europa 2020, y se concibe como uno de los instrumentos basados en el mercado que deben utilizarse para realizar estos objetivos. Más concretamente, en la estrategia Europa 2020 se espera de la contratación pública que mejore las condiciones generales que favorezcan la innovación por parte de las empresas, haciendo un uso pleno de las políticas de demanda, apoye el cambio hacia una economía que haga un uso más eficiente de los recursos y con bajas emisiones de carbono, por ejemplo, fomentando la generalización de una contratación pública ecológica, y mejore el entorno empresarial, en especial para las PYME innovadoras.

Habida cuenta del papel fundamental que se atribuye a la contratación pública para hacer frente a los retos que se presentan, resulta necesario modernizar las herramientas y los métodos existentes a fin de hacerlos más

para los cuales está pensado ese procedimiento.

6 El coste total que supone para la sociedad la contratación de los bienes y servicios a los que se aplican las Directivas se estima en unos 5.260 millones de euros por año (para el EEE-30 en 2009), que equivale a menos del 1,3\% del valor de las licitaciones publicadas (por la Unión Europea a 27) en el mismo período (esto es, 420.000 millones de euros). Esta estimación engloba la totalidad del coste soportado durante el proceso completo de contratación, es decir, desde la fase previa, pasando por la preparación de las ofertas por todos los licitadores participantes y la selección del adjudicatario, e incluye el coste de los posibles recursos y litigios.

7 Según un análisis econométrico realizado en el contexto de la evaluación, incluso un aumento elemental de la transparencia o apertura puede reportar un ahorro tangible. Así, la publicación de un anuncio de licitación da lugar a un ahorro del 1,2 \% en comparación con los contratos con respecto a los cuales no se publica ni un anuncio de licitación, ni un anuncio de información previa. La utilización del procedimiento abierto lleva aparejado un ahorro adicional del 2,6 \%. Sobre la base de estas conclusiones, un poder adjudicador que publica una convocatoria de licitación y recurre a un procedimiento abierto puede esperar obtener un beneficio total equivalente a un ahorro del 3,8 $\%$ sobre el valor final del contrato. En el caso del procedimiento restringido, el ahorro correspondiente es menor, situándose en torno al $2,5 \%$.

8 Europa 2020 es la estrategia de crecimiento de la Unión Europea para la próxima década, cuya finalidad no es solo superar la crisis que continúa azotando a muchas de nuestras economías, sino también subsanar los defectos de nuestro modelo de crecimiento y crear las condiciones propicias para un tipo de crecimiento distinto, más inteligente, sostenible e integrador. Para ello ha fijado cinco objetivos clave que la UE debe alcanzar al final de la década en los ámbitos de empleo, educación, investigación e innovación, integración social y reducción de la pobreza, y cambio climático y energía. La estrategia incluye además siete "iniciativas emblemáticas" que constituyen un marco en el que la UE y las administraciones nacionales pueden aunar esfuerzos y reforzarse mutuamente en áreas relacionadas con las prioridades de Europa 2020, como la innovación, la economía digital, el empleo, la juventud, la política industrial, la pobreza y el uso eficiente de los recursos. Más información sobre esta iniciativa puede encontrarse en http://ec.europa.eu/europe2020/index_es.htm Víd. además, la Comunicación de la Comisión de 3 de marzo de $2010(\operatorname{COM}(2010) 2020)$ 
adecuados para responder a la evolución del contexto político, social y económico. Por ello, el nuevo marco legislativo europeo de contratación pública persigue dos objetivos complementarios. El primero de esos objetivos es incrementar la eficiencia del gasto público es decir, se debe perseguir la máxima rentabilidad de las inversiones efectuadas en los contratos públicos. Para alcanzar este objetivo, es fundamental generar la competencia más fuerte posible por los contratos públicos que se adjudican en el mercado interior. Se debe dar a los licitadores la oportunidad de competir en condiciones equitativas y deben evitarse los falseamientos de la competencia. Al mismo tiempo, es crucial incrementar la eficiencia de los procedimientos de contratación como tales: la racionalización de los procedimientos de contratación, con medidas de simplificación específicamente adaptadas a las necesidades particulares de los pequeños poderes adjudicadores, podría ayudar a las Entidades contratantes a lograr los mejores resultados posibles de la contratación con la menor inversión posible, en términos de tiempo y de dinero público. Unos procedimientos más eficientes beneficiarán a todos los operadores económicos y facilitarán la participación de las PYME y de los licitadores transfronterizos. De hecho, la participación transfronteriza en los procedimientos de contratación pública en la UE sigue siendo baja. La comparación con el sector privado, donde el comercio transfronterizo es mucho mayor, muestra que hay un potencial considerable aún por aprovechar.

El segundo objetivo, complementario del anterior, es permitir que los compradores utilicen mejor la contratación pública en apoyo de objetivos sociales comunes, como proteger el medio ambiente, hacer un uso más eficiente de los recursos y de la energía y luchar contra el cambio climático, promover la innovación y la inclusión social y asegurar las mejores condiciones posibles para la prestación de servicios públicos de alta calidad. La búsqueda de este objetivo puede contribuir también a la realización del primero —un gasto público más eficiente a largo plazo — por ejemplo, al conceder menos prioridad al menor precio inicial en favor del menor coste del ciclo de vida.

\section{3.- Principales novedades que incorporan las nuevas Directivas de contratos públicos}

Como antes hemos señalado, el nuevo paquete legislativo europeo sobre contratos públicos está compuesto por tres Directivas, aprobadas por el Parlamento Europeo el 15 de enero de 2014 y que, tras su publicación, deberán ser incorporadas a los ordenamientos internos en el plazo máximo de dos años`. Estas nuevas Directivas «de cuarta generación», vienen a superar la lógica «armonizadora» de sus predecesoras y optan, como señala G. A. BENACCHIO (2012, pág. 8) por prescindir del establecimiento de reglas excesivamente rígidas e invasivas en favor de la promoción de los objetivos de simplificación y eficiencia.

Centrándonos en la Directiva relativa a la adjudicación de contratos públicos, por ser la que más influencia proyecta sobre los contratos de las Entidades Locales, las principales novedades podrían sistematizarse en torno a siete grandes bloques.

\section{a).- Simplificación y flexibilización de los procedimientos de contratación}

La nueva Directiva prevé la simplificación y flexibilización del régimen procedimental establecido por las actuales Directivas sobre contratación pública, aunque mantiene los principales instrumentos contenidos en la Directiva 2004/18. Así, en materia de procedimientos, se mantienen como tipos básicos el abierto y restringido, y como procedimientos especiales, sujetos a determinadas condiciones, el procedimiento de licitación con negociación, el diálogo competitivo y la asociación para la innovación (un nuevo tipo de procedimiento para la contratación innovadora). Por otro lado, se han acortado los plazos para la participación y la presentación de ofertas, lo que permite una contratación más rápida y más racional.

La Directiva también contempla un régimen menos oneroso para los poderes adjudicadores subcentrales que será desarrollado con mayor amplitud en el siguiente apartado. Baste apuntar ahora que estos compradores podrán utilizar un anuncio de información previa como convocatoria de licitación, quedando liberados, si utilizan esta posibilidad, de publicar un nuevo anuncio de licitación antes de poner en marcha el procedimiento de contratación. Asimismo, podrán fijar algunos límites temporales con mayor flexibilidad previo acuerdo con los participantes.

Por otra parte, se han revisado, a la luz de la jurisprudencia del Tribunal de Justicia de la Unión Europea, las definiciones de algunas nociones clave que determinan el ámbito de aplicación de la Directiva. Así sucede, por ejemplo, en relación con los encargos a medios propios y las relaciones de cooperación entre entidades públicas. En relación con los primeros, la Directiva recoge ahora toda la doctrina jurisprudencial sentada desde que, con

9 Las líneas estratégicas de la reforma fueron analizadas en el trabajo conjunto de A. RUIZ DE CASTAÑEDA y M. A. BERNAL BLAY, (2011, págs. 23 a 42). Un primer análisis de las propuestas puede encontrarse en J.M. GIMENO FELIÚ (2013, págs. 39 a 105); J.A. MORENO MOLINA (2013, págs. 113-162); y B. COLÓN DE CARVAJAL FIBLA (2012). Además, puede consultarse el monográfico dedicado a las nuevas Directivas en Revista Contratación Administrativa Práctica núm. 129 (2014, pp. 5-65). 
ocasión de la Sentencia de 18 de noviembre de 1999 (As. C-107/98, Teckal), se configuraran como excepción a la aplicación de la Directiva las adjudicaciones de contratos de obras, servicio o suministros a favor de entidades sobre la que se ostentase un control análogo al ejercido sobre los propios servicios que realizase la parte esencial de su actividad para el ente que realizaba el encargo ${ }^{10}$. La Directiva positiviza una definición de lo que debe entenderse por situación de control "análogo al ejercido sobre los propios servicios" (la posibilidad de influencia sobre las decisiones importantes y los objetivos estratégicos) incorporando la doctrina del Tribunal de Justicia sentada en su Sentencia de 13 de octubre de 2005, (Asunto C-458/03, Parking Brixen Gmbh). También se acoge la posibilidad de que ese control análogo pueda ser ejercido de manera conjunta por varias entidades, posibilidad que ya ha sido admitida también por el Tribunal de Justicia".

Junto a los supuestos de colaboración vertical con medios propios, la Directiva regula también, como otra forma de excepción a su aplicación, las relaciones de cooperación horizontal entre entidades contratantes, también aceptada por el Tribunal de Justicia en su Sentencia de 9 junio de 2009 (As. C-480/06, Comisión vs. República Federal de Alemania) ${ }^{12}$.

Otra importante novedad es la supresión de la tradicional distinción entre los servicios denominados prioritarios y no prioritarios (servicios «A» y «B») establecida en los Anexos II A y II B de la Directiva 2004/18. Debemos recordar que, conforme al art. 21 de dicha Directiva 2004/18, la adjudicación de contratos que tuviesen por objeto servicios incluidos en el anexo II B (categorías 17 a 27) sólo quedaba sujeta a las disposiciones contenidas en el artículo 23 (relativo al establecimiento de prescripciones técnicas) y al apartado 4 del artículo 35 (relativo a la publicación de un anuncio de adjudicación). Tras un estudio sobre la aplicación de la Directivas ha quedado demostrado que no queda justificado restringir la aplicación plena de la legislación sobre contratación a un grupo limitado de servicios (los servicios incluidos en el Anexo II A, esto es, categorías de servicios 1 a 16). Sin embargo, se establece un régimen jurídico especial para los contratos denominados «de servicios sociales», denominación bajo la que se ampara igualmente a otras categorías de servicios «a las personas», tales como los servicios de salud y los educativos.

\section{b).- Promoción de la contratación electrónica}

El uso de las comunicaciones electrónicas y el procesamiento electrónico de las transacciones por los poderes adjudicadores puede generar ahorros significativos y mejorar los resultados de la contratación, reduciendo a la vez despilfarros y errores. La Directiva continúa en este punto las conclusiones obtenidas tras la consulta a los operadores con ocasión del Libro Verde sobre la generalización del recurso a la contratación pública electrónica en la Unión Europea'13.

Se espera que con las medidas que ahora se incorporan en la Directiva los Estados miembros puedan realizar el cambio definitivo a la contratación electrónica. Para ello, la propuesta de Directiva establece la obligación de transmitir los anuncios en formato electrónico, poner la documentación de la contratación a disposición del

10 Pero junto a la positivación de la doctrina jurisprudencial sobre medios propios se observan algunas novedades. Así, en relación con el requisito del control análogo, la Directiva permite que pueda ser ejercido por vía indirecta, al señalar que puede ser ejercido por otra persona controlada por la entidad contratante. En relación con el segundo requisito Teckal, el relativo a la realización de la parte esencial de la actividad del medio propio para la entidad o entidades que lo controlan, la Directiva exige que más del 80 por ciento de esa actividad esté destinada a dicha entidad o entidades, lo cual supone, de facto, un endurecimiento del requisito. Para la determinación de dicho porcentaje se tomará en consideración la actividad del medio propio durante los tres años precedentes (y en los casos en los que no esté disponible la información sobre ese período -por ejemplo porque el medio propio no existiese en ese período- será suficiente las proyecciones de negocio). Por otra parte, la Directiva otorga además carta de naturaleza a los encargos «inversos» y «cruzados», al excepcionar igualmente del ámbito de aplicación de la Directiva los supuestos en los que cuando una entidad controlada que sea poder adjudicador adjudique un contrato a su controladora, o a otra persona jurídica controlada por el mismo poder adjudicador. Además, el requisito relativo a la ausencia de participación privada en el medio propio fijado por el Tribunal de Justicia en su Sentencia de 15 de enero de 2005 queda matizado en la Directiva, que admite tal participación del sector privado siempre que la misma no suponga la posibilidad de ejercer una influencia decisiva sobre el medio propio o permita bloquear sus decisiones. La Directiva, aun tratando de reducir los supuestos en los que resulta posible la participación privada en los medios propios parece haber olvidado los motivos que llevaron al Tribunal de Justicia en el 2005 (As. C-26/03, stadt Halle) a descartar la existencia de control sobre tales entidades análogo al ejercido sobre los propios servicios. Se indicaba entonces, por una parte, que "la relación entre una autoridad pública, que es una entidad adjudicadora, y sus propios servicios se rige por consideraciones y exigencias características de la persecución de objetivos de interés público. Por el contrario, cualquier inversión de capital privado en una empresa obedece a consideraciones características de los intereses privados y persigue objetivos de naturaleza distinta" (apartado 50), y en segundo lugar, que "la adjudicación de un contrato público a una empresa de economía mixta sin licitación previa perjudicaría al objetivo de que exista una competencia libre y no falseada y al principio de igualdad de trato de los interesados ... ya que, entre otras cosas, este procedimiento otorgaría a una empresa privada que participa en el capital de la citada empresa una ventaja en relación con sus competidores" (apartado 51).

11 Sentencias del Tribunal de Justicia 10 de septiembre (As C-573/07, Sea Srl) y 13 de noviembre de 2008 (As. C-324/07, Coditel), y también en la más reciente de 29 de noviembre de 2012 (Asuntos acumulados C-182/11 y C-183/11, Econord Spa). Sobre esta cuestión del control análogo ejercido de forma conjunta, puede verse mi artículo (2013, págs. 88-93).

12 Un análisis de esta Sentencia puede verse en mi trabajo "La cooperación administrativa horizontal como fórmula de organización (2011, págs.. 361-376)

$13 \operatorname{COM}(2010) 571$ final, de 18.10.2010.

REALA, n 2 julio-diciembre 2014, ISSN: 1989-8975 - DOI: http://dx.doi.org/10.24965/reala.v0i2.10193 
público por medios electrónicos y adoptar una comunicación totalmente electrónica, en particular por lo que respecta a la presentación electrónica de ofertas o solicitudes, en todos los procedimientos de contratación en un período de transición de dos años.

Asimismo, racionaliza y mejora los sistemas dinámicos de adquisición y los catálogos electrónicos, herramientas de contratación completamente electrónicas que se adaptan especialmente a la contratación muy agregada que llevan a cabo las centrales de compras. El instrumento de la contratación electrónica también permitirá a los poderes adjudicadores evitar, detectar y corregir los errores que se deben en general a una interpretación o comprensión incorrectas de las normas de contratación pública.

\section{c).- Utilización estratégica de la contratación pública en respuesta a nuevos desafíos}

Según los últimos datos publicados por la Comisión Europea, la contratación pública representa actualmente en España alrededor del 15,5 por ciento del PIB ${ }^{14}$. Como bien ha señalado MEDINA ARNÁIZ (2011), la contratación pública se ha convertido en un ámbito de actividad a través del cual poder orientar y afianzar comportamientos empresariales beneficiosos para el interés general sin que, necesariamente, estén conectados con la directa satisfacción funcional del contrato. En otros lugares se ha puesto ya de manifiesto que la contratación pública no puede ser considerada como un fin en si mismo sino que debe ser visualizada como una potestad o herramienta jurídica al servicio de los poderes públicos para el cumplimiento efectivo de sus fines o sus políticas públicas. Esto significa que los contratos públicos no constituyen exclusivamente un medio de abastecerse de materias primas o de servicios en las condiciones más ventajosas, sino que, en la actualidad, a través de la contratación pública, los poderes públicos realizan una política de intervención en la vida económica, social y política del país 15 . Es por ello que debemos concebir la contratación pública como un instrumento para llevar a cabo políticas públicas transversales ${ }^{16}$. La contratación puede, y debe ser, una técnica que permita conseguir objetivos sociales, ambientales o de investigación, en la convicción de que los mismos comportan una adecuada comprensión de cómo deben canalizarse los fondos públicos. EN palabras de GIMENO FELIÚ (2014, pág. 45), se impone, pues, una visión estratégica de la contratación pública alejada de la rígida arquitectura del contrato administrativo, concebido como sistema de aprovisionamiento de bienes y servicios.

Las nuevas Directivas acogen esa concepción instrumental de la contratación pública, proporcionando una serie de herramientas a los poderes adjudicadores para contribuir a la realización de los objetivos estratégicos de Europa $2020^{17}$. Lo que se pretende es utilizar el "poder de compra" de los poderes adjudicadores para comprar bienes y servicios que promuevan la innovación, el respeto del medio ambiente y la lucha contra el cambio climático mejorando al mismo tiempo el empleo, la salud pública y las condiciones sociales ${ }^{18}$.

Como ejemplos de esa utilización estratégica de la contratación pública, podemos mencionar en primer lugar la posibilidad que ofrece la Directiva a los compradores públicos de tomar en consideración el coste del ciclo de vida de los productos, los servicios o las obras que se van a comprar a la hora de adjudicar los contratos. El ciclo de vida abarca todas las etapas de la existencia de un producto, una obra o la prestación de un servicio, desde la adquisición de materias primas o la generación de recursos hasta la eliminación, el desmantelamiento o la finalización. Los costes que deben tenerse en cuenta para su cálculo no incluyen solo los gastos monetarios directos, sino también los costes medioambientales externos, si pueden cuantificarse en términos monetarios y

14 Public Procurement Indicators 2011, de 5 de diciembre de 2012. El valor estimado de los contratos que no superan los umbrales de aplicación de las Directivas de contratos públicos se estima en 102 billones a nivel de la Unión Europea, aunque no hay datos disponibles de lo que suponen en España según el Documento de trabajo de la Comisión Annual Public Procurement Implementation Review 2012 (SWD (2012) 342 final, de 9 de octubre de 2012), p.15.

15 Vid en este sentido Informe 17/2008, de 21 de julio la Junta Consultiva de Contratación Administrativa del Gobierno de Aragón.

16 BLAZQUEZ ROMÁN, J.A. y RAMÍREZ HORTELANO, P. (2005, pág. 39).

17 Vid. Comunicación de la Comisión Europa 2020 Una estrategia para un crecimiento inteligente, sostenible e integrador (COM(2010) 2020 de 3 de marzo de 2010). En esta Comunicación se señalan como prioridades de esta estrategia el crecimiento inteligente (desarrollo de una economía basada en el conocimiento y la innovación); crecimiento sostenible (promoción de una economía que utilice más eficazmente los recursos, que sea verde y más competitiva) y un crecimiento integrador: fomento de una economía con un alto nivel de empleo que redunde en la cohesión económica, social y territorial).

18 Con el título de Contratación pública estratégica, el prof. J. PERNAS GARCíA dirige un volumen que publica la editorial Aranzadi en 2014, y en el que se recogen estudios monográficos sobre "La contratación del sector público como política pública" (J. RODRÍGUEZARANA MUÑOZ); “Compra pública estratégica” (J.M. GIMENO FELIÚ); “Crisis económica y contratación pública” (C. AYMERICH CANO); “Contratación pública y pymes. un comentario a la luz de la propuesta de directiva en materia de contratación pública” (G. BARRIO GARCíA); "Contratos públicos y políticas de apoyo a las personas con discapacidad” (A.P. DOMíNGUEZ ALONSO y J.A. MORENO MOLINA); "El desarrollo de políticas activas de empleo a través de los contratos públicos” (Miguel BERNAL BLAY); “Comercio justo y contratación pública” (Teresa MEDINA ARNÁIZ); “Cambio climático, eficiencia energética y contratación pública” (J. PERNAS GARCÍA); “La compra pública innovadora en los sistemas europeo y español de contratación pública” (A. LÓPEZ MIÑO); “Promoción de la igualdad de género a través de la contratación pública” (P. VALCÁRCEL FERNÁNDEZ); “La contratación del conocimiento universitario en la encrucijada de la recesión” (C. AMOEDO SOUTO), y “Contratación pública y eficiencia energética” (J. PERNAS GARCÍA). 
verificarse. Con ello, se permitirá valorar positivamente las ofertas que presenten unos menores costes del ciclo de vida del producto o servicio que constituya el objeto del contrato. Igualmente, los poderes adjudicadores podrán hacer referencia a todos los factores directamente vinculados al proceso de producción en las especificaciones técnicas y en los criterios de adjudicación, siempre que se refieran a aspectos del proceso de producción que estén estrechamente relacionados con la producción de bienes o la prestación de servicios en cuestión.

En relación con determinados “servicios a la persona”, agrupados bajo la denominación (no muy afortunada en nuestra opinión) de "servicios sociales", la Directiva ha adoptado la decisión de someterlos a sus prescripciones cuando superen los 500.000 euros de valor estimado, quedando sometidos los contratos que no alcancen dicho umbral únicamente al respeto de los principios fundamentales de transparencia e igualdad de trato. La evaluación del impacto y la eficacia de la legislación sobre contratación pública de la Unión Europea puso de manifiesto que los servicios sociales, de salud y de educación tienen características específicas que hacen que la aplicación de los procedimientos habituales para la adjudicación de contratos públicos de servicios resulte inadecuada en esos casos. Estos servicios se prestan normalmente en un contexto específico que varía mucho de un Estado miembro a otro, debido a la existencia de distintas circunstancias administrativas, organizativas y culturales. Debido a que estos servicios tienen, por su naturaleza, una dimensión transfronteriza muy limitada ${ }^{19}$, los Estados miembros deben disponer de amplias facultades discrecionales para organizar la elección de los proveedores de servicios.

Por otra parte, la Directiva introduce algunas herramientas para promover la innovación a través de la contratación pública, consciente de que la investigación y la innovación desempeñan un papel central en la Estrategia Europa $2020^{20}$. En este sentido, la Directiva mantiene la exclusión de su ámbito de aplicación de las compras públicas precomerciales (art. 14), es decir, los servicios de investigación y desarrollo (I+D) previos a la comercialización de los productos o servicios (que cubre actividades como la exploración de soluciones que son propias de las fases de diseño, creación de prototipo, productos de prueba y preproducción, deteniéndose antes de la producción comercial y venta ${ }^{21}$. Por otra parte, para facilitar la adquisición de productos y servicios innovadores, la Directiva añade un procedimiento de adjudicación específico, la asociación para la innovación (art. 31), que podrá utilizarse para el desarrollo y la ulterior adquisición de productos, obras y servicios nuevos e innovadores, que, no obstante, deberán suministrarse dentro de los niveles de prestaciones y de costes acordados.

\section{d).- Mejora del acceso al mercado de los contratos públicos para las pequeñas y medianas empresas}

Con el fin de mejorar el acceso de las PYME a los contratos públicos, la Comisión publicó ya en 2008 el European Code of Best Practices facilitating access by SMEs to public procurement contracts ${ }^{22}$. La Directiva se basa en este trabajo y proporciona medidas concretas para eliminar los obstáculos de acceso al mercado para las PYME, al compartir la idea, ya expresada en el documento citado, de que las pequeñas y medianas empresas tienen un enorme potencial de creación de empleo, crecimiento e innovación. Facilitarles el acceso a los mercados de contratación puede ayudarles a liberar este potencial, al mismo tiempo que permitirá a los poderes adjudicadores ampliar su base de proveedores, lo cual redundará positivamente en un aumento de la competencia por los contratos públicos.

Como medidas específicas para facilitar el acceso de las PYMES al mercado de contratación pública, y que acompañarán a otras de alcance general ${ }^{23}$, la Directiva exige que los poderes adjudicadores dividan los contratos públicos en lotes — homogéneos o heterogéneos- con el fin de hacerlos más accesibles para las PYME. Si deciden no hacerlo, deberán explicar de manera específica su decisión.

La segunda medida "estrella", cuyos efectos pueden verse atenuados dado el carácter potestativo de la misma (los Estados miembros decidirán si la incorporan, o no, a sus Ordenamientos internos) consiste en la previsión de que los subcontratistas puedan solicitar que el poder adjudicador les pague directamente los suministros, las obras y los servicios proporcionados al contratista principal en el contexto de la ejecución del contrato (art. 71).

19 Un análisis cuantitativo del valor de los contratos para la adquisición de este tipo de servicios, adjudicados a operadores económicos extranjeros, ha mostrado que los contratos por debajo de este valor no tienen, en general, interés transfronterizo.

20 Vid. en este sentido la Comunicación de la Comisión Iniciativa emblemática de Europa 2020: Unión por la innovación (COM(2010) 546 final, de 6 de octubre de 2010). Según las últimas estimaciones, si hasta 2020 se alcanzara el objetivo de gastar en I+D un $3 \%$ del PIB se podrían crear 3,7 millones de puestos de trabajo y aumentar el PIB anual en cerca de 800000 millones de euros hasta 2025 (P. ZAGAMÉ: The cost of a non-innovative Europe, 2010.)

21 Sobre la misma, Vid. Comunicación de la Comisión La contratación precomercial: impulsar la innovación para dar a Europa servicios públicos de alta calidad y sostenibles, COM (2007) 799, de 14 de diciembre de 2007.

22 Documento de trabajo de los servicios de la Comisión, SEC(2008) 2193.

23 La simplificación general de las obligaciones de información en los procedimientos de contratación beneficiará considerablemente a las PYME. La propuesta prevé la obligación de aceptar las declaraciones de los interesados como prueba suficiente a efectos de selección. En la práctica, la presentación de pruebas documentales se verá facilitada mediante un documento normalizado (European Single Procurement Document) que servirá para demostrar la inexistencia de motivos de exclusión. 
Con esta medida se ofrece a los subcontratistas, que a menudo son PYME, un medio eficaz para proteger su interés por cobrar.

\section{e).- Ejecución de los contratos}

Por primera vez se introducen en las Directivas europeas de contratos públicos disposiciones específicas que inciden sobre la fase de ejecución de los contratos. Especialmente significativas son las disposiciones sobre modificaciones de los contratos, cuestión cada vez más pertinente y problemática para los profesionales ${ }^{24}$. Estas modificaciones quedan sujetas a un régimen muy estricto, y tendrán la consideración de nuevas adjudicaciones cuando supongan una alteración sustancial de las disposiciones de un contrato público, requiriendo por ello un nuevo procedimiento de contratación ${ }^{25}$. En particular, se considerará que se alteran las características esenciales de un contrato (art. 72):

(a) cuando la modificación introduzca condiciones que, de haber figurado en el procedimiento de contratación inicial, habrían permitido la selección de candidatos distintos de los seleccionados inicialmente o la adjudicación del contrato a otro licitador;

(b) cuando la modificación altere el equilibrio económico del contrato en beneficio del contratista;

(c) cuando la modificación amplíe de forma considerable el ámbito del contrato para abarcar suministros, servicios u obras no previstos inicialmente.

No se considerarán, en cambio, modificaciones sustanciales, aquellas cuya necesidad derive de circunstancias que un poder adjudicador diligente no podría prever (imprevisibles ${ }^{26}$ ), siempre que la modificación no altere la naturaleza global del contrato y que no conlleven un aumento del precio superior al $50 \%$ del valor del contrato inicial.

Importante resulta igualmente el tratamiento que la Directiva ofrece a la sustitución del contratista, supuesto que en nuestro Ordenamiento interno parece acoger la figura de la "cesión del contrato". Habrá que ver cómo se incorpora la previsión incluida en la Directiva según la cual "la sustitución del socio contractual se considerará una modificación sustancial”, salvo que tal sustitución obedezca a operaciones de reestructuración empresarial o insolvencia, y el contratista sea sustituido por otro operador económico que cumpla los criterios de selección cualitativa establecidos inicialmente.

\section{f).- Gobernanza}

En este apartado es donde más cambios ha habido desde que la propuesta de Directiva fue presentada. En general, las medidas más innovadoras en este campo no han encontrado el apoyo necesario y han decaído. No obstante, queda patente la idea de la Comisión de articular un sistema de información contractual fluido y dinámico que permita corregir eventuales problemas aplicativos de las Directivas

En este sentido, la primera Propuesta de Directiva contemplaba la creación de una Autoridad en cada Estado miembro encargada de la supervisión, aplicación y control de la contratación pública, con capacidad para proponer soluciones adecuadas a los problemas de carácter más estructural. Para reforzar la lucha contra la corrupción y el favoritismo, la propuesta de Directiva establecía la obligación de remitir los contratos celebrados al organismo de supervisión, para que éste pudiera examinar estos contratos a fin de detectar pautas sospechosas. Asimismo se contemplaba la creación de centros de conocimiento para ofrecer apoyo profesional especializado e independiente para tramitar proyectos de contratación complejos. Estos centros de conocimientos asistirían tanto a los compradores públicos como a las empresas, en particular las PYME.

24 Sobre la cuestión, tres recientes trabajos abordan ya la nueva regulación que contempla la Directiva. Son los trabajos de J.M. GIMENO FELIÚ “La modificación de los contratos: límites y derecho aplicable”, J.J. PARDO GARCíA-VALDECASAS “EI interés público y los principios comunitarios: su influencia en la modificación contractual”, y de E. HERNÁEZ SALGUERO “Visión crítica de la inclusión en el ámbito del recurso administrativo especial en materia de contratación de la modificación contractual”, incluidos en el monográfico sobre La contratación pública: problemas actuales editado por el Consejo Consultivo de la Comunidad de Madrid en 2013. A ellos debe unirse dos trabajos anteriores, de J.M. GIMENO FELIÚ (2011) y de J. COLÁS TENAS (2012)

25 Hace ya algún tiempo que tal concepción inspiraba la jurisprudencia del Tribunal de Justicia, y es ahora cuando esa doctrina obtiene un reconocimiento expreso a nivel de Derecho positivo. Cfr. Sentencias del Tribunal de Justicia de 29 de abril, de 2004 , Succhi di Frutta, de 19 de junio de 2008 (Pressetext Nachrichtenagentur GMBH), o la más reciente del

26 No se admiten, en cambio, las modificaciones que obedezcan a "necesidades nuevas". Sobre este concepto, en su reciente Sentencia de 31 de enero de 2013 (As. T 235/11, Comisión Vs. Reino de España), el Tribunal General de la Unión Europea desestima un recurso del Reino de España que pretendía la anulación de la Decisión de la Comisión C 20111 - 1023 final, de 18 de febrero de 2011 , por la que se reduce la ayuda del Fondo de Cohesión a distintas proyectos relativos a la ejecución de determinadas líneas ferroviarias de alta velocidad en España AVE -. La sentencia condena al Reino de España y critica que la legislación española permitiera la modificación por necesidades nuevas ya que tal concepto no forma parte de la noción de imprevisibilidad: "el uso de un criterio relativo a la apreciación de la existencia de necesidades nuevas permitiría a la entidad adjudicadora modificar a su arbitrio, durante la fase de ejecución del contrato, las propias condiciones de la licitación". 
La Propuesta de Directiva, al introducir dichas medidas era consciente de que su implantación generaría algunos costes, aunque se mostraba convencida de su neutralización por la reducción de los que se producen con ocasión de los litigios (tanto para los poderes adjudicadores como para las empresas) o los derivados de los retrasos en la adjudicación de los contratos, debido a la aplicación incorrecta de las normas de contratación pública o a la mala preparación de los procedimientos de contratación, así como de los costes que acarrean la fragmentación y la ineficiencia del asesoramiento que se ofrece actualmente a los poderes adjudicadores.

En su versión final, sin embargo, la Directiva prescinde de las Autoridades y Centros de conocimiento. En lugar de ello, en relación con la Gobernanza, la Directiva establece una obligación de monitorizar la aplicación de la normativa sobre contratos públicos, debiendo los Estados miembros enviar a la Comisión cada tres años un informe que señale los problemas aplicativos más frecuentes. Integrado en ese informe puede enviarse la información estadística relativa a los contratos no cubiertos por la Directiva. Además de esos informes trianuales, la Directiva contempla la necesidad de enviar a la Comisión informes individuales sobre cada contrato adjudicado conforme las prescripciones de la Directiva.

Por otra parte, para canalizar las relaciones entre los Estados miembros y la Comisión relativas a la aplicación de la normativa sobre contratación pública, los primeros deberán designar unos puntos de contacto (points of reference).

Por último, la Directiva prevé que los diferentes organismos nacionales compartan información y buenas prácticas, y cooperen, a través del Sistema de Información del Mercado Interior (IMI) establecido por el Reglamento 1024/2012 del Parlamento europeo y del Consejo, de 25 de octubre de $2012^{27}$.

\section{g).- Directiva relativa a la adjudicación de contratos de concesión.}

Por cuanto se refiere a la Directiva sobre adjudicación de contratos de concesión, su principal objetivo es aclarar el marco jurídico aplicable a la adjudicación de concesiones, así como delimitar claramente el ámbito de aplicación de dicho marco ${ }^{28}$. Las obligaciones específicas que deberán cumplirse en el ámbito de las concesiones aumentarán considerablemente la seguridad jurídica ya que, por un lado, los poderes y entidades adjudicadores contarán con unas disposiciones precisas que incorporen los principios del Tratado a la adjudicación de concesiones y, por otro, los operadores económicos dispondrán de algunas garantías básicas respecto al procedimiento de adjudicación.

En este sentido, como principales novedades, la nueva Directiva incluye una definición más precisa de contrato de concesión que hace referencia al concepto de riesgo operacional. En ella se deja claro qué tipos de riesgo se consideran operacionales y en qué consiste el riesgo significativo al señalarse que "el derecho a explotar las obras implica la transferencia al concesionario del riesgo operacional sustancial. Se considerará que el concesionario asume el riesgo operacional sustancial cuando no esté garantizado que vaya a recuperar las inversiones realizadas ni a cubrir los costes que haya contraído para explotar las obras que sean objeto de la concesión. El riesgo económico puede ser de los tipos siguientes: a) riesgo relacionado con la utilización de las obras o la demanda de prestación del servicio; b) riesgo relacionado con la disponibilidad de las infraestructuras proporcionadas por el concesionario o utilizadas para la prestación de servicios a los usuarios".

La propuesta de Directiva sobre concesiones también proporciona referencias respecto a la duración máxima de las concesiones, y modifica el ámbito de aplicación de las Directivas «Recursos» (Directivas 89/665/CEE y 92/13/ CE, modificada por la Directiva 2007/66/CE) para incluir en el mismo a los contratos de concesión cuyo valor estimado sea igual o superior a los 5 millones de euros.

27 El Sistema de Información del Mercado Interior («IMI») es una aplicación informática accesible a través de internet, realizada por la Comisión en colaboración con los Estados miembros, cuyo propósito es servir de ayuda a estos últimos para que puedan cumplir en la práctica las exigencias de intercambio de información establecidas en los actos jurídicos de la Unión a través de un mecanismo de comunicación centralizado que permita el intercambio transfronterizo de información así como la asistencia recíproca. En concreto, el IMI ayuda a las autoridades competentes a identificar a sus homólogas en otro Estado miembro, a gestionar el intercambio de información, incluso de los datos de carácter personal, basándose en procedimientos simples y unificados, y a superar las barreras lingüísticas gracias al uso de unos sistemas de tratamiento predefinidos y pretraducidos. Cuando sea posible, la Comisión debería proporcionar a los usuarios del IMI cualquier otra funcionalidad de traducción que se ajuste a sus necesidades, sea compatible con la seguridad y los requisitos de confidencialidad para el intercambio de información en el IMI y pueda ofrecerse a un coste razonable.

El objeto del IMI debe ser mejorar el funcionamiento del mercado interior proporcionando una herramienta eficaz y sencilla de usar para la cooperación administrativa entre los Estados miembros y entre los Estados miembros y la Comisión, de modo que se facilite la aplicación de los actos de la Unión.

28 Un primer análisis de la Directiva de concesiones lo ofrece X. LAZO VITORIA (2013, págs. 137-174). 


\section{II.- LA CONTRATACIÓN DE LOS «PODERES ADJUDICADORES SUB-CENTRALES»}

El Libro Verde sobre la modernización de la política de contratación pública de la Unión Europea publicado por la Comisión en $2011^{29}$ abordaba expresamente la contratación de los «pequeños poderes adjudicadores». Señalaba la Comisión entonces las quejas de estas entidades contratantes por tener que aplicar íntegramente el régimen de normas de procedimiento y salvaguardias para la adjudicación de sus relativamente pequeños contratos, exigiendo una cantidad desproporcionada de tiempo y esfuerzo.

Las quejas se hacían extensivas igualmente a la tramitación de los "pequeños contratos", aquellos que quedan por debajo de los umbrales de aplicación de las Directivas, ya que, en relación con los mismos existe cierta inseguridad jurídica, derivada de las dudas que suscita el alcance de los requisitos derivados del Derecho primario. Respecto de estos contratos no resulta infrecuente la incertidumbre reinante en cuanto al modo en que deben materializarse los principios de libertad de acceso a las licitaciones, publicidad y transparencia de los procedimientos, no discriminación e igualdad de trato entre los candidatos, la salvaguarda de la libre competencia y la selección de la oferta económicamente más ventajosa ${ }^{30}$.

Habida cuenta de las razones anteriores, planteaba la Comisión la posibilidad de establecer un marco procedimental más ligero para la adjudicación de contratos por encima de los umbrales de las Directivas, por los poderes adjudicadores locales y regionales. En el citado Libro Verde se preguntaba expresamente:

27. ¿Piensa que el régimen íntegro de contratación pública es apropiado o, por el contrario, inadecuado para las necesidades de los poderes adjudicadores más pequeños? Explique su respuesta.

28. En caso afirmativo, ¿estaría a favor de simplificar el régimen de contratación para la adjudicación de contratos relativamente pequeños por las autoridades regionales y locales? ¿Cuáles deberían ser, en su opinión, las características de ese régimen simplificado?

La Comisión planteaba la conveniencia de establecer un marco procedimental más ligero para los poderes adjudicadores locales y regionales, aprovechando todas las posibilidades de flexibilidad que ofrece el Acuerdo de Contratación Pública para las entidades subcentrales y los operadores de servicios públicos, sin comprometer el requisito de transparencia ${ }^{31}$. No obstante, el proceso de simplificación procedimental no está exento de

$29 \operatorname{COM}(2011) 15$ final, de 27 de enero de 2011.

30 Los procedimientos especiales y rigurosos previstos en las Directivas comunitarias sobre coordinación de los procedimientos de adjudicación de los contratos públicos se aplican únicamente a aquellos contratos cuyo valor sobrepase un determinado umbral previsto expresamente en cada una de ellas. Por tanto, las normas de esas Directivas no se aplican a los contratos cuyo importe no alcanza el umbral fijado en ellas. Sin embargo, ello no significa que esos últimos contratos estén excluidos del ámbito de aplicación del Derecho comunitario. En efecto, en lo relativo a la adjudicación de estos contratos, las entidades adjudicadoras están obligadas, no obstante, a respetar las normas fundamentales del Tratado en general y el principio de no discriminación por razón de la nacionalidad en particular.

Los principios de igualdad de trato y de no discriminación por razón de la nacionalidad, tal como han sido interpretados por la jurisprudencia del Tribunal de Justicia, implican en particular una obligación de transparencia, que permite que la autoridad pública concedente se asegure de que tales principios son respetados. Ello queda confirmado tanto por el noveno considerando de la Directiva 2004/17, sobre la coordinación de los procedimientos de adjudicación de contratos en los sectores del agua, de la energía, de los transportes y de los servicios postales, como por el segundo considerando de la Directiva 2004/18, sobre coordinación de los procedimientos de adjudicación de los contratos públicos de obras, de suministro y de servicios. De ello se deduce que tanto los Estados miembros como sus órganos de contratación deben respetar esta obligación de transparencia para la adjudicación de todos los contratos públicos, que consiste en garantizar, en favor de cualquier posible licitador, un grado de publicidad adecuado que permita la apertura del mercado a la competencia, así como el control de la imparcialidad de los procedimientos de adjudicación. Esta obligación comprende una forma de publicidad anterior a la adjudicación del contrato público de que se trata, en otras palabras, una publicidad previa que tiene lugar antes de la adjudicación. En efecto, una publicidad ex post no puede garantizar una publicidad adecuada.

Sobre las formas de manifestación de los principios enunciados Vid. la Comunicación interpretativa de la Comisión sobre el Derecho comunitario aplicable en la adjudicación de contratos no cubiertos o sólo parcialmente cubiertos por las Directivas sobre contratación pública de 23 de junio de 2006, así como la Sentencia del Tribunal General de 20 de mayo de 2010 (As. T-258/06) que resuelve un recurso de anulación contra la misma interpuesto por la República Federal de Alemania. Dicha Sentencia concluye que la Comunicación se limita a desarrollar las disposiciones relativas a la libre circulación de mercancías, a la libertad de establecimiento, a la libre prestación de servicios, los principios de no discriminación, de igualdad de trato y de proporcionalidad y las reglas de transparencia y de reconocimiento mutuo aplicables a la adjudicación de contratos no cubiertos o sólo parcialmente cubiertos por las Directivas sobre contratación pública y no establece obligaciones específicas o nuevas en comparación con tales disposiciones, principios y reglas, tal como han sido interpretadas por la jurisprudencia del Tribunal de Justicia. En tales circunstancias, no puede considerarse que dicha Comunicación produzca efectos jurídicos vinculantes que puedan afectar a la situación jurídica de los Estados miembros.

Sobre los principios aplicables a esta materia, por todos, me remito al trabajo de J. A. MORENO MOLINA (2012).

31 El Acuerdo sobre Contratación Pública (ACP) es, por ahora, el único acuerdo jurídicamente vinculante de la Organización Mundial del Comercio (OMC) que trata específicamente de la contratación pública. Es un tratado plurilateral administrado por un Comité de Contratación Pública, que está compuesto por los Miembros de la OMC que son Partes en el ACP y, por consiguiente, tienen derechos y obligaciones en 
dificultades. La creación de diferentes niveles de requisitos de procedimiento puede incrementar la complejidad del marco jurídico global y resultar difícil de transponer y aplicar en la práctica.

Las Directivas del año 2004 prevén cierta flexibilidad para los operadores de servicios públicos (ver en este sentido la Directiva 2004/17 del Parlamento Europeo y del Consejo, de 31 de marzo de 2004, sobre la coordinación de los procedimientos de adjudicación de contratos en los sectores del agua, de la energía, de los transportes y de los servicios postales), pero no para los poderes adjudicadores locales y regionales. Este tipo de sistema diferenciado daría a las entidades locales más libertad en su actividad de contratación y reduciría las cargas administrativas, precisamente en aquellas áreas en las que podrían ser desproporcionadas.

Otra posibilidad, que también planteaba la Comisión, era la de permitir la utilización generalizada del procedimiento negociado con publicación previa de un anuncio de licitación. Esta puede ser una buena manera de adaptar el contrato para tener en cuenta preocupaciones y necesidades específicas de esas entidades "pequeñas". Sin embargo, plantea un importante riesgo: no es seguro que los pequeños poderes adjudicadores tengan siempre el poder adquisitivo y la experiencia técnica necesarios para negociar en igualdad de condiciones con los licitadores. Y no son aislados los casos en los que los órganos que controlan la contratación han anulado procedimientos de contratación negociados por mala tramitación de los mismos ${ }^{32}$.

\section{1.- El concepto de «poder adjudicador sub-central» en la Directiva de adjudicación de contratos públicos}

La nueva Directiva sobre adjudicación de contratos públicos, al definir su ámbito de aplicación subjetivo, utiliza el concepto de "poder adjudicador" ("contracting authorities"), que integra al Estado, a las Regiones (en España las Comunidades Autónomas), las Entidades Locales, así como los organismos de Derecho público ${ }^{33}$ y las asociaciones formadas entre algunos de los anteriores.

La principal novedad que introduce la propuesta de Directiva es la distinción, como especies del género "poder adjudicador", entre "Autoridades gubernamentales -poderes adjudicadores- centrales" y "poderes adjudicadores subcentrales". Así, se entenderá por "Autoridades gubernamentales centrales" los poderes adjudicadores que figuran en el anexo I de la Directiva y, en la medida en que se introduzcan a escala nacional rectificaciones o modificaciones, las entidades que las sucedan. Utilizando un criterio definidor residual, tendrán la consideración de "poderes adjudicadores subcentrales" todos aquellos que no son las autoridades gubernamentales centrales, lo cual incluye, por supuesto, tanto a las autoridades regionales como a las locales. La Directiva identifica además los conceptos de "autoridades regionales" y de "autoridades locales" por remisión al Reglamento (CE) n 1059/2003 del Parlamento Europeo y del Consejo de 26 de mayo de 2003 por el que se establece una nomenclatura común de unidades territoriales estadísticas (NUTS) ${ }^{34}$.

El Reglamento núm. 1059/2003 clasifica las distintas unidades administrativas de los Estados miembros de la UE según su nivel 35 en la nomenclatura:

virtud del Acuerdo.

La versión actual del Acuerdo se negoció durante la Ronda Uruguay en 1994 y entró en vigor el $1^{\circ}$ de enero de 1996. El 15 de diciembre de 2011, los negociadores alcanzaron un acuerdo que plasma los resultados de la renegociación del Acuerdo. Esta decisión política fue confirmada el 30 de marzo de 2012 mediante la adopción formal de la Decisión sobre los resultados de las negociaciones.

El texto vigente del Acuerdo se encuentra disponible desde el enlace http://www.wto.org/spanish/tratop_s/gproc_s/gp_gpa_s.htm

32 En concreto, por falta de negociación. Vid en este sentido la Resolución 50/2011 de 24 de febrero de 2011, del Tribunal Administrativo Central de Recursos Contractuales, así como el Acuerdo 10/2013, de 14 de junio, del Tribunal de Contratos Públicos de Navarra. Indican estas Resoluciones que "la presentación de las ofertas por las empresas invitadas, no puede ser considerada como una fase de negociación, pues resulta obvio que la negociación de existir lo será con posterioridad a la presentación de las ofertas, no las ofertas en sí mismas.”

33 Tienen la consideración de «organismo de Derecho público» cualquier organismo:

a) creado específicamente para satisfacer necesidades de interés general que no tengan carácter industrial o mercantil,

b) dotado de personalidad jurídica y

c) cuya actividad esté mayoritariamente financiada por el Estado, los entes territoriales u otros organismos de Derecho público, o bien cuya gestión se halle sometida a un control por parte de estos últimos, o bien cuyo órgano de administración, de dirección o de vigilancia esté compuesto por miembros de los cuales más de la mitad sean nombrados por el Estado, los entes territoriales u otros organismos de Derecho público.

34 Para poder recopilar datos y elaborar y divulgar unas estadísticas regionales armonizadas, la Unión Europea ha establecido la nomenclatura común de las unidades territoriales estadísticas (NUTS). Esta clasificación sustituye a la establecida por Eurostat. Para que las estadísticas regionales sean comparables, las zonas geográficas deben tener una población comparable. La clasificación NUTS es jerárquica en la medida en que subdivide cada Estado miembro en tres niveles: NUTS 1, NUTS 2 y NUTS 3 . Los niveles NUTS 2 y NUTS 3 son subdivisiones respectivas de los niveles NUTS 1 y NUTS 2. Los Estados miembros pueden optar por un mayor grado de detalle y subdividir el nivel NUTS 3.

35 La definición de las unidades territoriales se basa en las unidades administrativas existentes en los Estados miembros. Una unidad administrativa designa una zona geográfica con una autoridad administrativa que tenga poder para tomar decisiones de carácter administrativo o político dentro del marco jurídico e institucional del Estado miembro. El nivel NUTS al cual pertenece una unidad administrativa se determina 
- NUTS 1: «Gewesten/Régions» en Bélgica; «Länder» en Alemania; «Continente», «Regiao dos Açores» y «Regiao da Madeira» en Portugal; «Scotland, Wales, Northern Ireland» y «Government Office Regions of England» en el Reino Unido.

- NUTS 2: «Provincies/Provinces» en Bélgica; «Regierungsbezirke» en Alemania; «Periferíes» en Grecia; «Comunidades y ciudades autónomas» en España; «Régions» en Francia; «Regions» en Irlanda; «Regioni» en Italia; «Provincies» en los Países Bajos; «Länder» en Austria.

- NUTS 3: «arrondissements» en Bélgica; «Amtskommuner» en Dinamarca; «Kreise/kreisfreie Städte» en Alemania; «nomoi» en Grecia; «provincias» en España; «départements» en Francia; «regional authority regions» en Irlanda; «provincie» en Italia; «län» en Suecia; «maakunnat/landskapen» en Finlandia.

Además de las anteriores, el Reglamento núm. 1059/2003 también recoge una categoría especial de “pequeñas unidades administrativas". Sería el caso de los «Gemeenten/Communes» en Bélgica; «Kommuner» en Dinamarca; «Gemeinden» en Alemania; «Demoi/Koinótites» en Grecia; «Municipios» en España (salvo algunos los que se agrupan en NUTS 3 -Ver Anexo I-); «Communes» en Francia; «Counties/County boroughs» en Irlanda; «Comuni» en Italia; «Communes» en Luxemburgo; «Gemeenten» en los Países Bajos; «Gemeinden» en Austria; «Freguesias» en Portugal; «maakunnat/landskapen» en Finlandia; «Kommuner» en Suecia y «Wards» en el Reino Unido.

Así, a efectos de la Directiva de contratos públicos tendrán la consideración de "autoridades regionales" todas las autoridades de las unidades administrativas incluidas en los niveles NUTS 1 y 2, mientras que serán consideradas "autoridades locales" las unidades administrativas incluidas en el nivel NUTS 3 y también las unidades administrativas menores a que se hace referencia en el Reglamento núm. 1059/2003 citado.

\section{2.- Especialidades de los contratos de los «poderes adjudicadores sub-centrales» en la nueva Directiva}

La distinción, conforme a los criterios anteriores, de una categoría de "poderes adjudicadores subcentrales" encuentra su justificación en la previsión de algunas especialidades en relación con los procedimientos de adjudicación que tramiten estas entidades.

\section{a).- Contratos de servicios sujetos a regulación armonizada.}

La primera de esas especialidades afecta a los contratos que quedan comprendidos en el ámbito de aplicación de la Directiva. Con carácter general, la Directiva resulta de aplicación contratos públicos de obras de valor estimado igual o superior a 5.186.000 €, así como a los contratos de servicios y suministros cuyo valor estimado supera igualmente un determinado umbral. Es en relación con ese umbral que prevé la Directiva para los contratos de servicios y suministros donde encontramos la primera diferencia de régimen jurídico entre los contratos de los poderes adjudicadores centrales y los subcentrales. Así, los contratos de servicios y suministros de los poderes adjudicadores centrales quedarán sometidos a las prescripciones de la Directiva cuando su valor estimado sea igual o superior a los $134.000 €$. En cambio, para que un contrato de suministros o de servicios de un poder adjudicador subcentral quede sujeto a las prescripciones de la Directiva, su valor estimado deberá ser igual o superior a los $207.000 €^{36}$.

\section{b).- Utilización de anuncios de información previa como anuncios de licitación}

La Directiva prevé también la posibilidad de que los poderes adjudicadores subcentrales queden sujetos a unos requisitos de publicación de las licitaciones menos estrictos. En este sentido, el art. 48.2 de la Directiva admite que, en determinados casos, los poderes adjudicadores subcentrales puedan adjudicar un contrato sin publicar un anuncio de licitación, aliviando con ello una importante carga procedimental y reduciendo el plazo de tramitación del procedimiento.

Tal posibilidad está prevista para aquellos supuestos en los que para la adjudicación del contrato se utilice un procedimiento restringido o un procedimiento con negociación, y siempre que se haya anunciado previamente la intención de adjudicar el contrato mediante la publicación de un anuncio de información previa. Según indica el

a partir de umbrales demográficos. Así para el nivel NUTS 1 el mínimo de población son 3 millones de habitantes hasta un máximo de 7 millones; el nivel NUTS 2 oscila entre los 800.000 y los 3 millones de habitantes, mientras que el nivel NUTS 3 precisa de un mínimo de 150.000 habitantes y alcanza hasta los 800.000 .

Si la población total de un Estado miembro no llega al umbral mínimo de un nivel de la NUTS, todo el territorio de ese Estado constituye una unidad territorial NUTS de ese nivel. Si, en un Estado miembro, no existen unidades administrativas de tamaño suficiente para incluirse en un nivel determinado de la nomenclatura, este nivel se constituye agrupando un número adecuado de unidades administrativas contiguas de menor tamaño. Las unidades formadas de este modo se llaman «unidades no administrativas».

36 Cfr. Reglamento (UE) número 1336/2013 de la Comisión, de 13 de diciembre de 2013, por el que se modifican las Directivas 2004/17/CE, 2004/18/CE y 2009/81/CE, del Parlamento Europeo y del Consejo, en lo que concierne a sus umbrales de aplicación en materia de procedimientos de adjudicación de contratos. Ese umbral económico es revisado cada dos años y puede oscilar al alza o a la baja. 
antecitado precepto:

2. Para los procedimientos restringidos y de licitación con negociación, los poderes adjudicadores subcentrales podrán utilizar un anuncio de información previa como convocatoria de licitación con arreglo a lo dispuesto en el artículo 26, el apartado 5, siempre que el anuncio cumpla todas las condiciones siguientes:

(a) que se refiera específicamente a los suministros, las obras o los servicios que serán objeto del contrato que vaya a adjudicarse;

(b) que mencione que el contrato se adjudicará por procedimiento restringido o negociado sin ulterior publicación de una convocatoria de licitación e invite a los operadores económicos interesados a que manifiesten su interés por escrito;

(c) que contenga, además de la información indicada en el anexo V, parte B, sección I, la información indicada en el anexo $\mathrm{V}$, parte $\mathrm{B}$, sección II;

(d) que se haya enviado para su publicación entre 35 días y doce meses antes de la fecha de envío de la invitación a la que se hace referencia en el artículo 54, apartado $1^{37}$.

Esta posibilidad de utilizar los anuncios de información previa como convocatoria de licitación queda condicionada a la observancia de determinados límites, igualmente señalados en la Directiva. El primero de ellos es que tal posibilidad no puede utilizarse si para la adjudicación del contrato se utiliza un procedimiento abierto, ya que queda ceñida, exclusivamente, a los procedimientos restringidos y con negociación (con publicidad).

Los operadores económicos que, a la vista del anuncio de información previa publicado, manifiesten su interés en participar en la licitación, deberán ser invitados posteriormente, antes de comenzar la fase de selección de licitadores, a confirmar su interés por escrito mediante una "invitación a confirmar el interés". Las "invitaciones a confirmar el interés" se enviarán simultáneamente a todos los interesados, y en las mismas se incluirá una referencia a la dirección electrónica en la que se hayan puesto directamente a disposición por medios electrónicos el pliego de condiciones o el documento descriptivo y cualquier documentación complementaria, tal y como indica el art. 54.2 de la Directiva. Además de lo anterior, el Anexo IX de la Directiva señala un contenido mínimo que debe incluirse en esas "invitaciones a confirmar el interés»:

(a) características y cantidad, incluidas todas las opciones relativas a contratos complementarios $y$, cuando sea posible, el plazo estimado previsto para ejercer dichas opciones; cuando se trate de contratos renovables, características y cantidad y, cuando sea posible, fechas estimadas de publicación de los futuros anuncios de licitación para las obras, suministros o servicios que vayan a ser objeto de licitación;

(b) tipo de procedimiento: restringido o de licitación con negociación;

(c) en su caso, fecha de comienzo o de finalización de la entrega de suministros o de la ejecución de obras o servicios;

(d) dirección y fecha límite de presentación de solicitudes de la documentación de la contratación, así como lengua o lenguas en que esté autorizada su presentación;

(e) dirección postal de la entidad que adjudicará el contrato y suministrará la información necesaria para la obtención del pliego de condiciones y demás documentos;

(f) condiciones de carácter económico y técnico, garantías financieras e información exigida a los

37 El período cubierto por el anuncio de información previa puede ser más amplio cuando se trate de la adjudicación de contratos de servicios sociales. 
operadores económicos;

(g) el importe y las modalidades de pago de la cantidad que haya que abonar para obtener la documentación de la contratación;

(h) naturaleza del contrato que constituye el objeto de la invitación a licitar: compra, arrendamiento financiero, arrendamiento o alquiler con opción de compra, o varias de estas formas, $y$

(i) los criterios de adjudicación y su ponderación o, cuando corresponda, el orden de importancia de dichos criterios, en caso de que esta información no figure en el anuncio de información previa, en el pliego de condiciones ni en la invitación a licitar o a negociar.

Por otra parte, cuando se utilicen los anuncios de información previa como anuncios de licitación, la Directiva señala que "tales anuncios no se publicarán en un perfil de comprador38" (perfil de contratante, en la terminología que utiliza el TRLCSP), como es la regla general para los anuncios de información previa (Cfr. art. 48.1 de la Directiva). Lo que quiere indicar tal prescripción es que los anuncios de información con los que se pretenda sustituir un anuncio de licitación posterior no podrán ser publicados únicamente en el perfil de contratante de la entidad adjudicadora, sino que necesariamente deberán ser enviados a la Comisión para su publicación en el DOUE. Con ello se quiere evitar el efecto perverso que sobre la competencia de los operadores económicos podría llegar a provocar la reducción de la accesibilidad a los anuncios de los contratos, máxime en casos como el español, donde el acceso a los perfiles de cada comprador (de cada contratante) no se encuentra unificado, sino fuertemente fragmentado ${ }^{39}$, al hacerse a través de la sede electrónica de cada entidad contratante. Solamente si el acceso a estos perfiles de comprador se hiciera a través de un punto único, y desde allí existiese la posibilidad de, utilizando un sistema efectivo de búsquedas, podría plantearse la posibilidad de que los anuncios de información previa con efecto sustitutivo de los anuncios de licitación pudieran publicarse sin afectar a la concurrencia en los perfiles de comprador de las entidades contratantes.

\section{c).- Flexibilidad en la determinación de los plazos de presentación de ofertas en determinados procedimientos de adjudicación}

La tercera especialidad de los contratos celebrados por los poderes adjudicadores subcentrales la encontramos en la duración de algunos procedimientos. La Directiva, con carácter general, ha optado por una reducción de los plazos de tramitación de los procedimientos. Así, en relación con el procedimiento abierto, el plazo mínimo para la presentación de ofertas será de 35 días a partir de la fecha de envío del anuncio de licitación (reducción de 17 días con respecto a lo señalado en la Directiva 20014/18). En el mismo sentido, el plazo mínimo para la recepción de las solicitudes de participación en los procedimientos restringidos y negociados con publicidad será de 30 días a partir de la fecha de envío del anuncio de licitación (frente a los 47 días que exige la Directiva 20014/18), y además, se asegura un plazo mínimo para la recepción de ofertas de 30 días a partir de la fecha en que se envíe la invitación a licitar en el caso de los procedimientos restringidos (40 días según la Directiva 2004/18), así como de 30 días a partir de la fecha de envío de la invitación, en el caso de procedimientos de licitación con negociación ${ }^{40}$.

La Directiva prevé una especialidad en relación con los plazos de presentación de ofertas en el marco de procedimientos restringidos o procedimientos de licitación con negociación que tramiten los poderes adjudicadores subcentrales. El art. 28.4 de la Directiva, en relación con el procedimiento restringido, señala que,

Los poderes adjudicadores subcentrales podrán establecer el plazo para la recepción de las ofertas de mutuo acuerdo con los candidatos seleccionados, siempre que todos los candidatos dispongan de un plazo idéntico para preparar y presentar sus ofertas. Cuando no sea posible llegar a un acuerdo sobre el plazo para la recepción de ofertas, el poder adjudicador fijará un plazo que no podrá ser inferior a 10 días a partir de la fecha de envío de la invitación a licitar.

La misma posibilidad resulta aplicable igualmente a los procedimientos de licitación con negociación por

38 La "precaución" anterior, sin embargo, no resulta aplicable a la publicación adicional a nivel nacional que debe realizarse en virtud del artículo 52 de la Directiva, que esa sí que podrá hacerse en el perfil de comprador (de contratante) de la entidad adjudicadora.

39 La dispersión de los perfiles de contratante, como ha señalado GIMENO FELIÚ (2013.2), produce fragmentación del mercado, potenciando la compra del "cercano" e impidiendo el efectivo funcionamiento, por inadecuada concurrencia, de las economías de escala.

40 Recuérdese que el cómputo de estos días debe realizarse en días naturales, de conformidad con lo dispuesto en el Reglamento (CEE, Euratom) n 1182/71 del Consejo, de 3 de junio de 1971, por el que se determinan las normas aplicables a los plazos, fechas y términos. 
disposición del inciso final del art. 29.1 de la Directiva. Con esta previsión, los poderes adjudicadores podrán flexibilizar los límites temporales para la presentación de las ofertas previo acuerdo con los participantes, beneficiándose así de la posibilidad de reducir el plazo de tramitación de los procedimientos. Obviamente, esta facultad de adaptación de los plazos de presentación de ofertas queda restringida a la tramitación de procedimientos restringidos y procedimientos de licitación con negociación que, en atención a su valor estimado, entren dentro del ámbito de aplicación de la Directiva. No resulta posible extender esta regla de simplificación procedimental a otros procedimientos, como es el caso de los procedimientos abiertos.

\section{III.- UNA REFLEXIÓN FINAL: SOBRE LA TRANSPOSICIÓN DEL RÉGIMEN DE CONTRATACIÓN DE LAS ENTIDADES LOCALES AL ORDENAMIENTO INTERNO}

Para terminar, entendemos necesario realizar una pequeña reflexión de orden sistemático en relación con la forma en que las especialidades que presenta la contratación de las Entidades Locales en las nuevas Directivas deberían incorporarse a la legislación española sobre contratación pública. En este sentido, entendemos que tales especialidades deberían recogerse en la normativa de contratos del sector público sistematizadas de una manera más coherente que como lo están ahora en el Real Decreto Legislativo 3/2011, de 14 de noviembre, por el que se aprueba el texto refundido de la Ley de Contratos del Sector Público (TRLCSP).

La normativa estatal sobre contratación pública ha señalado tradicionalmente ciertas «normas específicas de contratación de las Entidades Locales». Entre los textos más modernos puede citarse la Disposición Adicional novena de la Ley 13/1995, de 18 de mayo, de Contratos de las Administraciones Públicas, que luego se mantendría en el Texto Refundido aprobado por Decreto Legislativo 2/2000, de 16 de junio, así como, más recientemente, la Disposición Adicional segunda de la LCSP que hoy mantiene la misma numeración en el TRLCSP. Entender que las especialidades de la contratación de las Entidades locales se agotan en dicha disposición supone desconocer por completo la realidad de la contratación. Existen, dispersas por su articulado, otras especialidades de la contratación de las Entidades Locales, como son la posibilidad de aprobar pliegos de cláusulas administrativas generales (art. 114.3 TRLCSP); la publicidad sustitutoria de los anuncios de licitación en el Boletín Oficial de la respectiva provincia (art. 142.1 TRLCSP); la posibilidad de constituir las garantías que sean precisas, en efectivo y mediante certificados de inmovilización de los valores de Deuda Pública, mediante su depósito en la Caja de depósitos de la Entidad Local contratante (art. 96.a, 98.2 y 103.3 TRLCSP); o la posibilidad de que se atribuya la competencia para resolver los recursos especiales en materia de contratación interpuestos en relación con contratos de una Entidad Local a un órgano distinto de aquél que conoce de los recursos interpuestos contra contratos de la Comunidad autónoma en cuyo territorio se integre dicha Entidad, como es la regla general (art. 41.4 TRLCSP); la creación de centrales de contratación por las Diputaciones Provinciales (art. 204.2 TRLCSP) o su adhesión a sistemas externos de contratación centralizada (art. 205 y Disposición Adicional vigésimo octava TRLCSP).

Las opciones de ordenación sistemática que sigue la normativa española son dos. Por una parte, la opción unificada, que sigue el TRLCSP, de manera que la normativa general sobre contratos públicos ejerce una vis atractiva sobre las especialidades de los sujetos contratantes. El segundo modelo, seguido por ejemplo por la normativa foral de contratos públicos, opta por incluir las especialidades de la contratación de las Entidades Locales en la norma de cabecera que ordena su organización, régimen competencial y de organización de las Entidades Locales. Así, junto a la Ley Foral 6/2006 de 9 de junio de Contratos Públicos, modificada recientemente por Ley Foral 3/2013 de 25 de febrero, encontramos un completo título (el VI) en la Ley Foral 6/1990 de la Administración Local de Navarra (también modificado recientemente por la Ley Foral 4/2013 de 25 de febrero) que recoge las especialidades de los contratos de las entidades locales de Navarra o subvencionadas por éstas que se encuentren sujetos a la legislación foral de contratos públicos.

Desde el punto de vista sistemático nuestra propuesta es la de abandonar el modelo que sigue actualmente el TRLCSP, que incluye tales especialidades en una única Disposición Adicional (aunque encontramos más especialidades dispersas a lo largo del articulado). Nuestra propuesta de ordenación sistemática se alinea con la opción ya sugerida por el propio Consejo de Estado en su Informe 514/2006, de 25 de mayo, sobre el Anteproyecto de Ley de Contratos del Sector Público:

«... incluir en la legislación sobre contratos las especialidades de la contratación local, no parece que la ubicación más adecuada para ello sea una disposición adicional. Frente a ello cabrían dos posibilidades: 0 bien se podría incluir una nueva división en la ley que en su rúbrica hiciese referencia a las especialidades de la contratación local y en la que figurase, desglosado en artículos, el contenido de la actual disposición adicional segunda; o bien se podrían ir introduciendo las especialidades de la contratación local al hilo de los distintos aspectos del régimen de la contratación del sector público. En opinión de este Consejo sería preferible la primera opción.» 
Es decir, lo que, a nuestro juicio debería hacerse, es recoger en un Título de la Ley, rubricado como "Contratos de la Administración local", todas las especialidades relativas a organización y procedimiento que caracterizan los contratos públicos celebrados por las Entidades locales, procediendo a su desarrollo posterior en el articulado de la norma (y no en una disposición adicional). Y quizás, como medida complementaria, no estaría de más devolver a su ubicación original, la Ley de Bases de régimen local, las reglas de distribución de competencias para contratar entre los diferentes órganos que forman parte de la Administración local, que sería su lugar natural.

\section{BIBLIOGRAFÍA}

BENACCHIO Gian Antonio (2012) "Verso le Direttive di quarta generazione", en G. A. BENACCHIO/M. COZZIO Gli appalti pubblici: tra regole europee e nazionali, Egea, Milán.

BLAZQUEZ ROMÁN, J.A.y RAMÍREZ HORTELANO, P.: "Las cláusulas sociales en la contratación administrativa”, Contratación Administrativa Práctica núm. 42, 2005, pág. 39.

BERNAL BLAY, Miguel Ángel (2011): "La cooperación administrativa horizontal como fórmula de organización. Su articulación en el ámbito local desde la óptica del Derecho de los contratos públicos”, en GIMENO FELIÚ J.M. (Coord.) Organización Local, Nuevas tendencias, Civitas, Cizur Menor, pp. 361-376

(2013) "El control análogo sobre los medios propios y su ejercicio colectivo por varias entidades", Revista Contratación administrativa práctica, núm. 124, págs. 88-93.

CARBONERO GALLARDO, José Miguel (2012) “El colapso de la contratación administrativa”, artículo publicado en la Tribuna de opinión del Observatorio de contratación pública (www.obcp.es) el 26 de marzo de 2012.

COLÁS TENAS, Jesús (2012) “La reforma de la legislación de contratos del sector público en la ley de economía sostenible: El régimen de modificación de los contratos del sector público", Revista Española de Derecho Administrativo núm. 153, págs. 253-276.

COLÓN DE CARVAJAL FIBLA, Borja (2012): "Hacia una nueva Directiva de Contratos Públicos", en revista digital Noticias jurídicas, mayo 2012

GIMENO FELIÚ, José María (2011) “El régimen de la modificación de contratos públicos: regulación actual y perspectivas de cambio", Revista española de derecho administrativo, 149, págs. $29-54$.

(2013) “Las nuevas directivas -cuarta generación- en materia de contratación pública. Hacia una estrategia eficiente en compra pública”, Revista Española de Derecho Administrativo núm. 159 (2013), págs. 39.105;

(2013.2) "Unidad de mercado y Contratación Pública: redefiniendo los perfiles del contratante", Comentario publicado en la Tribuna del Observatorio de Contratación Pública (www.obcp.es) el 18 de marzo de 2013.

(2014) “Compra pública estratégica”, en el libro colectivo dirigido por J. PERNAS GARCíA Contratación pública estratégica, Aranzadi.

LAZO VITORIA, Ximena (2013) “El futuro del mercado concesional en Europa”, en CEFLEGAL num.154, págs. 137-174.

MEDINA ARNÁIZ, Teresa (2011) “Comprando para asegurar nuestro futuro: la utilización de la contratación pública para la consecución de los objetivos políticos de la Unión Europea”, en J.M. GIMENO FELIÚ y M.A. BERNAL BLAY (Dir./Coord.) Observatorio de los Contratos Públicos 2010, Civitas, Cizur Menor, pp. 43 a 94.

MORENO MOLINA, José Antonio (2013) "La cuarta generación de directivas de la Unión europea sobre contratos públicos", en J.M. GIMENO FELIÚ y M.A. BERNAL BLAY (Dir/Coord.) Observatorio de contratos públicos 2012, Civitas, 2013, pp. 113-162;

(2012) «El sometimiento de todos los contratos públicos a los principios generales de contratación» en el Liber ami-corum Tomás-Ramón Fernández, Thomson, Pamplona, 2012, págs. 3429 y ss. del tomo II.

PERNAS GARCÍA, José (2014) Contratación pública estratégica, Aranzadi.

RUIZ DE CASTAÑEDA, Alfonso y BERNAL BLAY, Miguel Ángel (2011): "La contratación pública y el Derecho comunitario. Cuestiones pendientes", en J.M. GIMENO FELIÚ y M.A. BERNAL BLAY (Dir/Coord.) Observatorio de los Contratos Públicos 2010, Civitas, Cizur Menor, 2011, pp. 23 a 42.

V.V.A.A (2013) La contratación pública: problemas actuales, Consejo Consultivo de la Comunidad de Madrid. Es aquí donde pueden verse trabajos sobre la modificación de contratos de J.M. GIMENO FELIÚ "La modificación de los contratos: límites y derecho aplicable", J.J. PARDO GARCÍA-VALDECASAS "El interés público y los 
principios comunitarios: su influencia en la modificación contractual”, y de E. HERNÁEZ SALGUERO "Visión crítica de la inclusión en el ámbito del recurso administrativo especial en materia de contratación de la modificación contractual".

V.V.A.A. (2014) "Estudio sobre nuevas Directivas de contratación pública", en Revista Contratación Administrativa Práctica núm. 129 (2014, págs. 5-65). 
